\title{
Qualidade de vida do profissional intérprete de língua de sinais
}

\section{Quality of life of sign language interpreters}

\section{Calidad de vida del professional intérprete del lenguaje de signos}

\author{
Ana Cristina Guarinello* \\ Tania Rodrigues Lisboa* \\ Adriano de Souza Pereira* \\ Israel Bispo dos Santos* \\ Luci Teixeira Iachisnki* \\ Jair Mendes Marques* \\ Ronaldo Quirino da Silva*
}

\section{Resumo}

Objetivo: O objetivo deste trabalho foi avaliar aspectos associados à qualidade de vida de intérpretes de língua de sinais e buscar relações com sua atuação profissional. Métodos: Trata-se de estudo transversal quantitativo, cuja coleta de dados se deu por meio da aplicação de dois questionários, um de caracterização da atuação desses profissionais no ambiente de trabalho e pelo questionário SF-36 da OMS. Participaram 25 intérpretes com idade média de 36,16 anos. Foram calculados média e desvio-padrão para os escores dos questionários. Utilizou-se o teste ANOVA de Friedman. Resultados: Os resultados demonstram que nos domínios capacidade funcional, dor, estado geral de saúde, vitalidade e saúde mental existe diferença significativa, sendo que a capacidade funcional é mais bem avaliada pelos participantes. Conclusão: Percebe-se que para grande parte dos participantes o ato de interpretar causa dor, estresse psicológico e alterações no seu estado geral de saúde, além da perda de vigor, força, energia e disposição.

Palavras-chave: Qualidade de vida; Saúde do trabalhador; Transtornos traumáticos cumulativos.

\footnotetext{
*Universidade Tuiuti do Paraná, Curitiba, PR, Brasil.

Contribuição dos autores:

ACG: trabalhou na concepção, delineamento, análise, interpretação dos dados e na redação final;

TRL:trabalhou na pesquisa, metodologia, análise, interpretação dos dados e na redação final;

ASP: trabalhou na pesquisa, metodologia, delineamento, análise e interpretação dos dados e na redação final;

IBS: trabalhou na pesquisa, metodologia, delineamento, análise e interpretação dos dados;

LTI: trabalhou na pesquisa, metodologia, delineamento, análise e interpretação dos dados e na redação final;

JMM: trabalhou na pesquisa, metodologia, análise e interpretação dos dados;

RQS: trabalhou na pesquisa, metodologia, delineamento.
}

E-mail para correspondência: Ana Cristina Guarinello - ana.guarinello@utp.br Recebido: $21 / 10 / 2017$

Aprovado: 25/06/2017 


\section{Abstract}

Objective: This study aims to evaluate aspects related to Sign Language interpreter's quality of life and relates it with their professional activities. Methods: It is a quantitative cross-sectional study, and data were collected by application of a characterization questionnaire and by SF -36 of the WHO. Twenty-five interpreters participated with average age of 36.16 years. The Friedman ANOVA test was used. Results: The results demonstrate that between functional capacity, pain, general health, mental health and vitality there were significant differences, and that functional capacity is best assessed by the participants. Conclusion: It is noticed that for most participants the act of interpreting causes pain, psychological stress and changes in their general health, besides loss of vigor, strength, energy and disposal.

Keywords: Quality of life; Occupational health; Cumulative trauma disorders.

\section{Resumen}

Objetivo: El objetivo de este trabajo fue evaluar los aspectos asociados con la calidad de vida de los intérpretes de lengua de signos y buscar relaciones con su actuación profesional. Métodos: Se trata de un estudio transversal cuantitativo en el que la recolección de datos fue a través de dos cuestionarios, uno de caracterización de la actuación de los profesionales en el ambiente de trabajo y otro por el SF36 de la OMS. Participaron 25 intérpretes con un pormedio de edad de 36,16 años. Fueron calculados pormédio y desviación estándar para las puntuaciones de los cuestionarios. Se utilizó la prueba ANOVA de Friedman. Resultados: Los resultados muestran que en los domínios capacidad funcional, dolor, salud general, vitalidad y salud mental hay una diferencia significativa, y la capacidad funcional se evalúa mejor por los participantes. Conclusión: Se puede observar que para la mayoría de los participantes el acto de interpreter causa dolor, estrés psicológico y cambios en el estado general de salud, además de pérdida de vigor, fuerza, energía y disposición.

Palabras clave: Calidad de vida; Salud laboral; Trastornos traumáticos acumulativos.

\section{Introdução}

Atualmente, em razão das leis de acesso que garantem que os surdos estudem em escolas regulares e da legitimação da Língua Brasileira de Sinais (Libras) $)^{1}$ como língua da comunidade surda brasileira, a língua de sinais e os surdos vêm ganhando um maior espaço social, especialmente no espaço escolar. A partir de tais leis, os profissionais intérpretes de língua de sinais passam a ser inseridos no espaço escolar.

Cabe esclarecer que a história da constituição desse profissional iniciou-se por meio de atividades voluntárias, e que apenas em 2010 tal classe foi reconhecida profissionalmente por meio da Lei $12.319 / 10^{2}$. Essa lei regulamentada no território nacional explicita em seu artigo $6^{\circ}$ que o tradutor e intérprete possui atribuições relacionadas à sua profissão, tais como: realizar a comunicação entre surdos e ouvintes; interpretar as atividades didático-pedagógicas e culturais que são desenvolvidas em instituições de ensino (fundamental, médio e superior), viabilizar o acesso do aluno surdo aos conteúdos do currículo; atuar em processos seletivos para cursos em instituições de ensino, dentre outras.

Ressalta-se que a lei 12.319/10² sem dúvida trouxe vários benefícios para os profissionais que atuam nessa área, tais como: a definição de seu papel, a abertura de alguns concursos federais para tal categoria, a visibilidade dos mesmos frente ao processo de acessibilidade dos surdos brasileiros, etc. Porém é preciso esclarecer que a mesma não traz em seu conteúdo nenhum artigo a respeito da saúde e da qualidade de vida desse profissional. É preciso esclarecer que a saúde ocupacional dos trabalhadores deveria ser evidenciada no Brasil, já que os riscos à saúde podem ocasionar um fim de carreira precoce para os trabalhadores.

Segundo a Organização Mundial da Saúde $(\mathrm{OMS})^{3}$, entende-se qualidade de vida como "a percepção do indivíduo de sua posição na vida, no contexto de sua cultura e no sistema de valores em que vive e em relação a suas expectativas, seus padrões e suas preocupações". No caso da qualidade 
de vida dos profissionais intérpretes de língua de sinais percebe-se que este profissional necessita ter consciência de seu próprio corpo no espaço, a fim de utilizá-lo com maior e melhor aproveitamento. Essa consciência corporal permitirá que os intérpretes tenham uma melhor qualidade de vida ao realizar a tradução da língua oral falada pelo professor ouvinte para a língua de sinais dos alunos surdos, ou seja, para ouvir uma língua auditiva oral e traduzi-la para outra de modalidade gestual-visual.

Segundo uma pesquisa ${ }^{4}$,os intérpretes de língua de sinais, além de muitas vezes sofrerem pressões psicológicas devido à carga horária extensa e ao próprio trabalho de tradução simultânea de uma língua para outra, também estão expostos a várias intempéries como, por exemplo, movimentos repetitivos e constantes em membros superiores, como pescoço, mão, antebraço etc. Tais movimentos podem causar dores e esforços repetitivos, os quais afetam diretamente a qualidade de vida desses profissionais.

Em vista disso, é fundamental prevenir a saúde dos tradutores e intérpretes de língua de sinais e conhecer as causas patológicas mais comuns adquiridas no exercício dessa profissão, que, em geral, variam desde lesões em tendões, músculos e articulações, principalmente dos membros superiores, ombros e pescoço, até a manutenção de posturas inadequadas o que resulta em dor, fadiga e declínio do desempenho profissional ${ }^{4}$.

É possível verificar na legislação a respeito da saúde do trabalhador, várias referências à doença ocupacional DORT (distúrbios osteomusculares relacionados ao trabalho), antiga LER (lesões por esforço repetitivo) $)^{5}$. Os DORT têm sido apontados como problemas de saúde pública em muitos países industrializados. Tais lesões, em geral, são resultado da combinação da sobrecarga das estruturas anatômicas do sistema osteomuscular com a falta de tempo para sua recuperação. A sobrecarga pode ocorrer tanto pela utilização excessiva de determinados grupos musculares em movimentos repetitivos com ou sem exigência de esforço localizado, quanto pela permanência de segmentos do corpo em determinadas posições por tempo prolongado, particularmente quando essas posições exigem esforço ou resistência das estruturas musculoesqueléticas contra a gravidade. A necessidade de concentração e atenção do trabalhador para realizar suas atividades e a tensão imposta pela organização do trabalho, também são fatores que interferem de forma significativa para a ocorrência dos DORT.

Os DORT podem ser desencadeados por vários fatores físicos, organizacionais e ainda psicossociais ${ }^{5}$. No caso dos tradutores e intérpretes de Libras podem-se elencar como fatores físicos relacionados aos DORT: movimento repetitivo excessivo; força muscular exagerada; postura prolongada ou incorreta; condicionamento físico insuficiente. Com relação aos fatores organizacionais, podem ser causas dos DORT a natureza repetitiva do trabalho; ausência de rodízios e pausas na organização do trabalho; inadequação do posto de trabalho; obrigatoriedade de manter o ritmo acelerado para atingir as metas de produtividade e jornadas prolongadas de trabalho. Os fatores psicossociais podem ser relacionados a quadros de ansiedade, depressão e, principalmente, de estresse ocupacional. Tal estresse é percebido de forma subjetiva por cada trabalhador, mas em geral, relaciona-se à ausência de autonomia, pressões cotidianas, perfeccionismo, carga e ritmo de trabalho excessivos, etc. Além disso, há "exigências cognitivas que podem ter um papel no surgimento das LER/DORT, seja causando um aumento de tensão muscular, seja causando uma reação mais generalizada de estresse" 6 .

Segundo pesquisa americana $^{7}$, a profissão de tradutor e intérprete de língua de sinais é uma das profissões com mais riscos ergonômicos, especialmente no que diz respeito às extremidades do corpo, há um aumento nos níveis de estresse cognitivo e mental e maior risco de desenvolver lesões musculoesqueléticas como a tendinite.

Corroborando com essas conclusões ${ }^{8}$ cabe destacar que há uma precariedade de políticas emergenciais que atentem para as questões de saúde do tradutor e intérprete de língua de sinais, assim como uma ausência de investimentos nas capacitações e formações desse profissional.

Considerando tais aspectos, o objetivo deste trabalho foi avaliar a qualidade de vida de intérpretes de língua de sinais que atuam na área educacional, por meio do SF-36 e de um questionário que caracterizava a atuação profissional desses participantes.

\section{Métodos}

Este é um estudo transversal de natureza quantitativa, a coleta de dados ocorreu por meio da aplicação de dois instrumentos: um questionário de 
caracterização dos participantes no que concerne a sua atuação como intérprete de língua de sinais na área educacional e o genérico da Organização Mundial de Saúde SF-36.

Para seleção dos intérpretes, optou-se por selecionar aqueles que atuam no ensino na área educacional de uma cidade no sul do Brasil. A aplicação dos instrumentos ocorreu no período de fevereiro a maio de 2016.

A amostra foi composta por 25 intérpretes, que após terem sido convidados para participar da pesquisa responderam aos questionários individualmente e assinaram o termo de consentimento livre e esclarecido (TCLE), no qual ficava explícito que não haveria ônus algum e que a pesquisa seria realizada por meio de respostas aos dois questionários.

Para coleta de dados foi utilizado o Medical Outcomes Short-Form Health Survey (SF-36), instrumento que permite uma avaliação genérica de saúde e que foi originalmente criado na língua inglesa. É constituído por 36 questões, que abrangem oito componentes: capacidade funcional, aspectos físicos, dor, estado geral da saúde, vitalidade, aspectos sociais, aspectos emocionais e saúde mental. Tal instrumento já traduzido e validado para a língua portuguesa é dividido em duas partes; a primeira avalia o estado de saúde e a segunda o impacto da doença na vida diária do paciente. As 36 questões são estruturadas em escalas, com algumas possibilidades de pontuação e são pontuadas de acordo com normas pré-estabelecidas.

Além disso, todos os participantes responderam a um questionário sobre a caracterização geral da amostra com perguntas sobre: idade, gênero, escolaridade, função, quantidade de horas que atua como intérprete, se essa quantidade de horas é excessiva, se sente dores no corpo ou na cabeça ao interpretar, ruído em sala de aula e se possui pausa para interpretar.

As análises estatísticas foram realizadas com a utilização de métodos descritivos (tabelas com distribuição de frequências, média, mínimo, máximo e desvio padrão) e métodos inferenciais (ANOVA de Friedman e o teste de diferença de proporções, ao nível de significância de 0,05 ). O software utilizado foi o Statistica - versão 13.1.

Esta pesquisa seguiu as normas regulamentadoras em seres humanos e foi aprovada pelo Comitê de Ética da UNESP - Universidade Estadual Paulista, Campus de Marília, Faculdade de Filosofia e Ciência, em 21/08/2013, conforme o protocolo $n^{\circ} 0782 / 2013$.

\section{Resultados}

Com relação às respostas do questionário que caracteriza a amostra, verifica-se que a idade média dos participantes é 36,16 anos com desvio padrão de 9,83 anos (idade mínima de 19 anos e máxima de 55).

$\mathrm{O}$ perfil dos participantes quanto ao gênero, escolaridade e função está representado na Tabela 1. Através de frequências absolutas e relativas (\%) e do teste de diferença de proporções, observou-se que não existe diferença significativa $(p=0,3961)$ entre as proporções de homens e mulheres. Além disso, percebeu-se que a proporção de intérpretes com ensino superior é significativamente superior em relação ao ensino médio $(\mathrm{p}=0,0297)$ e em relação aos especialistas ( $\mathrm{p}=0,0128)$. A maioria atua como intérprete da língua de sinais, sendo essa proporção significativamente superior $(p=0,000)$ em relação às demais funções. 
Tabela 1. Distribuição da amostra segundo sexo, escolaridade e função

\begin{tabular}{ccc}
\hline Variável e categoria & Frequência & \% \\
\hline Sexo & 14 & $56 \%$ \\
Feminino & 11 & $44 \%$ \\
Masculino & & \\
Escolaridade & 6 & $24 \%$ \\
Ensino Médio & 14 & $56 \%$ \\
Ensino Superior & 5 & $20 \%$ \\
Especialista & & \\
Função & 21 & $84 \%$ \\
TILS & 2 & $8 \%$ \\
Professor & 1 & $4 \%$ \\
Auxiliar de serviços gerais & 1 & $4 \%$ \\
Promotor de vendas & &
\end{tabular}

Com relação à carga horária semanal que atua como intérprete de língua de sinais a média é de 38,95 horas, com carga horária máxima de 60 horas semanais.

Como o questionário SF-36 possui perguntas sobre dor, mas não específicas sobre dores ao interpretar, os participantes ao responderem o questionário de caracterização da amostra foram questionados se sentem dores ao interpretar. Um pouco menos da metade da amostra, ou seja, $44 \%$ dos participantes responderam que sim. Todos os participantes que relataram que têm algum tipo de dor ao interpretar trabalham 40 horas semanais ou mais.

Dos intérpretes que responderam que sentem dor ao interpretar constatou-se que $9 \%$ sentem dor em membros superiores, $9 \%$ em partes não especificadas, $36 \%$ no tronco e $46 \%$ em mais de uma região do corpo, sendo essa última proporção significativamente superior em relação aos que sentem dor em membros superiores e em partes não especificadas ( $p=0,0034)$.

Outra questão diz respeito ao ruído em sala de aula: $68 \%$ desses participantes responderam que o ruído em sala de aula não atrapalha seu trabalho, enquanto $32 \%$ relataram que os ruídos atrapalham e dificultam seu trabalho, sendo a proporção dos participantes cujo ruído não atrapalha em sala de aula significativamente superior $(p=0,0109) \mathrm{em}$ relação aos demais.

Em relação a dores de cabeça ao interpretar, $4 \%$ relataram que sempre sentem dores de cabeça, $12 \%$ sentem dores leves, $16 \%$ raramente sentem dor de cabeça, $20 \%$ às vezes sentem dores de cabeça e
$48 \%$ nunca sentem dores de cabeça ao interpretar. A proporção dos que nunca sentem dores de cabeça é significativamente superior aos demais casos: sempre $(p=0,0004)$, dores leves $(p=0,0055)$, raramente sentem $(p=0,0153)$ e às vezes $(p=0,0366)$

Além das perguntas sobre dor, no questionário de caracterização da amostra havia uma pergunta relacionada ao excesso de carga horária de trabalho e com que frequência esse excesso ocorria. Percebe-se que $28 \%$ dos participantes raramente excedem a carga horária, porém $24 \%$ disseram que às vezes isso ocorre e $12 \%$ que isso sempre ocorre. Não ocorreram diferenças significativas nessa questão.

Ao serem questionados se possuem pausa para interpretar, $16 \%$ da amostra respondeu que não e $84 \%$ que sim, sendo a proporção dos que possuem pausa para interpretar significativamente superior $(p=0,0000)$ em relação aos que não possuem. Com relação ao tempo de intervalo, $5 \%$ dos entrevistados afirmam ter cinco minutos de intervalo, $10 \%$ têm dez minutos de intervalo, $15 \%$ afirmam ter quinze minutos para descanso, $20 \%$ vinte minutos, $30 \%$ trinta minutos, $5 \%$ quarenta e cinco minutos e $15 \%$ uma hora de descanso. As diferenças entre os tempos de intervalos não foram significativas.

Os resultados encontrados na aplicação do SF36 estão apresentados na Tabela 2 , sendo possível constatar por meio da ANOVA de Friedman, ao nível de significância de 0,05 (5\%), a existência de diferenças significativas $(p=0,0007)$ entre os domínios. A identificação das diferenças mostra que a capacidade funcional difere significativamente dos 
domínios: dor $(\mathrm{p}=0,0027)$, estado geral de saúde $(\mathrm{p}=0,0126)$, vitalidade $(\mathrm{p}=0,0005)$ e saúde mental $(\mathrm{p}=0,0053)$, apresentando média superior a esses domínios. Também se verificou a existência de diferença significativa entre o domínio vitalidade e estado geral de saúde $(p=0,0303)$ e aspecto emocional $(\mathrm{p}=0,0045)$, sendo que o domínio vitalidade apresenta média inferior a esses dois domínios.

Tabela 2. Medidas descritivas apuradas no SF-36 dos 25 intérpretes em relação aos diferentes domínios e resultado do teste estatístico.

\begin{tabular}{cccccc}
\hline Domínio & N & Média & Mínimo & Máximo & Desvio padrão \\
\hline Capacidade funcional & 25 & 85,00 & 55 & 100 & 14,86 \\
Aspectos físicos & 25 & 78,00 & 0 & 100 & 33,32 \\
Dor & 25 & 70,24 & 20 & 100 & 26,13 \\
Estado geral de saúde & 25 & 74,32 & 30 & 100 & 21,79 \\
Vitalidade & 25 & 65,60 & 25 & 95 & 20,17 \\
Aspectos sociais & 25 & 78,00 & 25 & 100 & 21,23 \\
Aspectos emocionais & 25 & 70,67 & 0 & 100 & 38,87 \\
Saúde mental & 25 & 71,36 & 24 & 92 & 19,89 \\
\hline
\end{tabular}

\section{Discussão}

Cabe esclarecer ao leitor que a discussão será apresentada a partir do cruzamento de dados dos dois questionários.

Este estudo demonstra que apesar de não haver uma diferença significativa entre homens e mulheres na amostra, pode-se perceber uma predominância de mulheres. Este fato também foi confirmado em outra pesquisa recente ${ }^{10}$ que delineia que há uma predominância de mulheres atuando nesta profissão, tendência esta presente em todos os seguimentos da área da educação. Além disso, percebe-se nesta amostra uma diferença significativa entre os intérpretes que possuem formação em nível superior e aqueles com outros níveis de formação. Esses resultados também foram apontados em outros estudos ${ }^{11,12}$; apesar disso, a maioria ainda não tem formação no nível superior na área de interpretação.

Com relação aos domínios apontados na tabela 2, capacidade funcional, dor, estado geral de saúde, vitalidade e saúde mental percebe-se que existe diferença significativa, sendo a capacidade funcional o domínio que melhor foi avaliado pelos participantes. Os resultados obtidos a partir das respostas do SF-36 demonstram que os participantes deste estudo percebem que os componentes dor, estresse psicológico, alterações no seu estado geral de saúde, perda de vigor, força, energia e disposição tiveram escores piores.
A tabela 2 também demonstra que o domínio vitalidade apresenta média inferior quando relacionado aos domínios estado geral de saúde e aspecto emocional. Tal resultado parece demonstrar que grande parte desses profissionais sente-se cansado com o trabalho de interpretação, sem o vigor e a energia necessários para o desempenho de sua função. É preciso esclarecer que tais condições adversas à saúde geral, predispõem o sujeito a irritações, dores e estresse, os quais prejudicam o trabalho desses profissionais. Percebe-se a partir desses dados, que ações de promoção da saúde são fundamentais nos espaços de trabalho, para que tanto os intérpretes quanto as pessoas que com eles trabalham possam tomar consciência, refletir e discutir a respeito de ações transformadoras da realidade no que tange às condições e organização do trabalho nas instituições de ensino, tornando esses espaços em ambientes saudáveis que considerem a qualidade de vida daqueles que ali atuam ${ }^{13}$.

Um dos fatores que pode ter relação especialmente com o domínio da dor, saúde mental e vitalidade relaciona-se com a carga horária semanal que esses participantes atuam como intérpretes de língua de sinais. A média de trabalho foi de 38,95 horas semanais, sendo que alguns participantes atuam até 60 horas semanais, revelando inclusive que extrapolam a carga horária semanal dedicada a interpretação. É preciso esclarecer que essa carga horária é excessiva para um profissional que fica exposto a um processo de tradução e interpretação 
de uma segunda língua. Esses profissionais interpretam conteúdos específicos de disciplinas específicas, os quais exigem uma concentração maior de atenção e escuta podendo levá-los a desgastes mentais e físicos. Ressalte-se que mesmo que a maioria dessa amostra tenha revelado que possui pausa para interpretar, tal fato não justifica uma carga horária de trabalho tão elevada.

Pesquisa $^{12}$ revela, como no estudo aqui apresentado, que muitos intérpretes atuam mais de 31 horas semanais, em um trabalho exaustivo, principalmente porque muitos deles referem atuar em mais de uma instituição, interpretando frequentemente temas bastante distintos. Muitos intérpretes manifestam estresse, dores musculares e sofrem muita cobrança, não apenas por parte das instituições, mas também por parte dos alunos surdos com relação ao seu desempenho no trabalho. Cabe observar que o ato de interpretar não é apenas mecânico, mas envolve questões linguísticas e cognitivas do profissional, e que em vista disso, podem ocorrer desgastes físicos e mentais nesses sujeitos ${ }^{10}$.

Essa carga horária excessiva também pode levar esses profissionais a sentir dores e desgastes físicos, tal como apontado por quase metade da amostra. A literatura ${ }^{7,10}$ esclarece que é fundamental prevenir a saúde dos tradutores e intérpretes de Libras e conhecer as causas patológicas mais comuns adquiridas no exercício dessa profissão, que variam desde lesões em tendões, músculos e articulações, principalmente dos membros superiores, ombros e pescoço, até a manutenção de posturas inadequadas o que pode resultar em dor, fadiga e declínio do desempenho profissional.

Os estudos brasileiros ${ }^{8,10,11}$ em torno dessas questões são escassos, assim ainda é difícil identificar as causas das doenças ocupacionais nos intérpretes, e pouco se sabe a respeito das complicações e queixas que a interpretação da língua de sinais pode causar em relação a doenças ocupacionais. Mas, já se sabe que as interpretações prolongadas sem um período de descanso levam a um risco de lesões principalmente nos membros superiores ${ }^{7,14}$. Pesquisa brasileira ${ }^{10}$ revela que $7 \%$ dos intérpretes participantes de um estudo atestam Lesão por Esforço Repetitivo (LER) e 9\% atestam doenças musculares crônicas ocasionadas pelo trabalho como intérprete.

A literatura internacional aponta que os intérpretes de línguas de sinais apresentam um aumento no risco de lesões músculoesqueléticas ${ }^{14,15,16}$.
Portanto, é preciso refletir a respeito de ações para promoção da saúde e melhoria da qualidade de vida dos intérpretes, que levem em conta as demandas e condições de uso do corpo, favorecendo a resistência, o descanso físico e o aprimoramento da saúde dos trabalhadores.

Além do desgaste físico, o ato de interpretar também pode causar um desgaste intelectual, tal como aponta uma pesquisa ${ }^{17}$ que esclarece que a tradução entre línguas pode causar esse tipo de desgaste. Além disso, o fato de ter que competir com os ruídos auditivos dentro da sala de aula dificulta o trabalho intelectual do intérprete, que precisa fazer um esforço maior para ouvir a fala do professor em meio ao ruído e traduzi-la para outra língua. A pesquisa aqui apresentada demonstra que $32 \%$ dos participantes referem que os ruídos de sala de aula atrapalham seu trabalho de escutar o professor, além disso, 36\% dos participantes mencionaram que o desgaste intelectual para interpretar resulta em dores de cabeça.

Há que se considerar, portanto, que ao intérprete cabe não só a transferência linguística entre duas línguas, mas é preciso levar em conta aspectos culturais e situacionais, para que haja sentido na interpretação de uma língua para outra. Além disso, o trabalho de traduzir e tornar os conteúdos acessíveis aos alunos faz com que tais profissionais precisem ter conhecimentos específicos dos alunos, dos conteúdos e dos professores regentes o que torna essa profissão bastante complexa ${ }^{11}$.

Percebe-se, assim, que, além da habilidade com cada uma das línguas envolvidas, os intérpretes precisam estar constantemente atualizados em relação ao conhecimento específico dos temas abordados, com leituras e aprofundamento que nem sempre ocorrem, o que muitas vezes converge em prejuízos nos resultados da interpretação ${ }^{12}$.

É preciso também destacar que alguns estados brasileiros estabelecem em seus documentos, que o profissional intérprete que atua na educação básica deveria ter uma carga horária de 20 a 40 horas semanais, e que nessa carga horária deveria estar incluída a função de oferecer apoio pedagógico aos alunos surdos em todas as disciplinas previstas na matriz curricular. Ora, como é possível fazer isso trabalhando uma média de 38 horas semanais atuando em sala de aula, ou pior, 60 horas por semana. Como tal profissional pode preservar sua saúde e qualidade de vida atuando sem pausas? 
Na perspectiva de se vislumbrar propostas de promoção da saúde nas instituições de ensino em que o profissional intérprete atua junto às pessoas surdas, é preciso pensar em ações que protejam a atuação desse profissional, e que levem em conta sua saúde e qualidade de vida.

\section{Conclusão}

Os resultados do presente estudo demonstram, através do questionário SF-36, que os melhores escores relacionam-se aos domínios capacidade funcional, aspectos físicos e sociais. Os menores escores foram nos domínios dor, vitalidade, aspectos emocionais e saúde mental.

Os resultados a partir do questionário de caracterização da amostra evidenciam que quase metade da amostra refere dores em mais de uma região do corpo ao interpretar, além disso, boa parte dos participantes afirmou sentir dores de cabeça ao interpretar e que o ruído de sala de aula os atrapalha. Percebe-se também que a maioria da amostra atua interpretando dentro de sala de aula por quase 40 horas semanais e muitos ainda não possuem pausa para interpretar. Esses resultados parecem ser um indicativo de que esses profissionais podem apresentar distúrbios ocupacionais relacionados especialmente aos membros superiores, associados a um conjunto de movimentos repetitivos e posturas ergonomicamente incorretas de toda a estrutura corporal. Além disso, o excesso de interpretações diárias, sem intervalos para repouso dos intérpretes, favorece o aparecimento de lesões por esforços repetitivos e do estresse com as atividades diárias.

Conclui-se, portanto, que há necessidade de esses profissionais conhecerem os fatores de risco profissional, evitando assim o aparecimento dos DORT e do estresse mental e físico ocasionado pelo trabalho. É preciso então propor encaminhamentos para programas preventivos a fim de que esses profissionais trabalhem com mais saúde e qualidade de vida visando que se evitem afastamentos ou até mesmo dispensas do trabalho por afecções relacionadas ao trabalho repetitivo.

Para que isso ocorra é fundamental que se realizem mais estudos com essa parcela da população que levem em conta os riscos de distúrbios ocupacionais desencadeados por esse tipo de trabalho e a qualidade de vida profissional dos intérpretes de língua de sinais.

\section{Referências}

1. Lei n ${ }^{\circ} 10.436$ de 24 de Abril de 2002. Dispõe sobre a Língua Brasileira de Sinais - Libras e dá outras providências. Ministério da Educação. Secretaria de Educação Especial.

2. Lei $\mathrm{n}^{\circ} 12.319$ de $1^{\circ}$ setembro de 2010. Regulamenta a profissão de Tradutor e Intérprete da Língua Brasileira de Sinais - LIBRAS. Ministério da Educação.

3. OMS. Organização Mundial da Saúde. [acesso em 18 ago 2016].Disponível em http://www.who-int/about/es/.

4. Woodcock K; Fischer, SL. Occupational Health and Safety for Sign Language Interpreters. Toronto ON: Ryerson University, 2008.

5. Norma Regulamentadora 17. Estabelece parâmetros que permitam a adaptação das condições de trabalho às características psicofisiológicas dos trabalhadores, de modo a proporcionar um máximo de conforto, segurança e desempenho eficiente. Ministério do Trabalho.- São Paulo, 1992.

6. Instrução Normativa INSS/DC, $\mathrm{n}^{\circ} 98$ de 5 de dezembro de 2003. Aprova Norma Técnica sobre Lesões por Esforços Repetitivos-LER ou Distúrbios Osteomusculares Relacionados ao Trabalho DORT. Ministério da Previdência social. INSS. 2003.

7. Rit Study. 2008. Sign Language Interpreters at High Ergonomic Risk - Interpreting places greater stress on extremities than industrial activities. [acesso em 12 out 2015]. Disponível em http://www.rit.edu/news/story.php?id=46110.

8. Santos O. Travessias históricas do tradutor/intérprete de libras: De 1980 a 2010. Artifícios. Rev Difere; 2012; 2(4): 9.

9. Ware JR JE, Sherbourne CD. The MOS 36-itemshort form health survey (SF-36). Conceptual framewotk and item selection. Med care; 1992; 30(6): 473-83.

10. Martins DA, Machado VLC. Educação bilíngue para surdos: um olhar a partir da trajetória de intérpretes de Língua Brasileira de Sinais. ETD; 11(1): .234-54.

11. Silva RQ, Guarinello AC, Martins SESO. O intérprete de libras no contexto do ensino superior. Rev Teias; 2016; 17(46): 177-90.

12. Lacerda CBF, Gurgel TMA. Perfil de tradutores intérpretes de Libras (TILS) que atuam no ensino superior no Brasil. Rev bras educ esp; 2011; 17(3): 1-17.

13. Gonçalves CGO, Penteado RZ, Silvério KCA. Fonoaudiologia e saúde do trabalhador: a questão da saúde vocal do professor. Saúde Rev; 2005; 7(15):45-51.

14. Feuerstein M, Fitzgerald T. Biomechanical Factors Affecting Upper Extremity Cumulative Trauma Disorders in Sign Language Interpreters. J Occup Med; 1992; 34(3):.257-64.

15. Johnson WL, Feuerstein M. An Interpreter's Interpretation: Sign Language Interpreters' View of Musculoskeletal Disorders. J Occup Rehabil; 2005; 15: 401-15.

16. Feuerstein M, Carosella AM, Burrell LM, Marshall L, DeCaro J. Occupational upper extremity symptoms in sign language interpreters: prevalence and correlates of pain, function, and work disability. J Occup Rehab; 1997; 7: $187-205$.

17. Meals R, Payne W, Gaines R. Functional Demands and consequences of Manual Communication. J Hand Surgery; 1998; 13A: 686-91. 